\title{
Measuring the Risk and Performance in Plantation Sector Using CAPM Based Jensen's Alpha
}

\author{
D.A.I. Dayaratne \\ D.G Dharmaratne \\ SA Haris \\ Department of Accountancy and Finance \\ Sabaragamuwa University, Belihuloya
}

\begin{abstract}
This paper evaluates the company performance using the CAPM Based Jensen's Alpha.

The CAPM of Sharpe (1964), Lintner (1965) and Mossin is a widely used model in modern Finance to estimate cost of equity and company performance. We carried out our study for ten plantation companies listed on Colombo Stock Exchange (CSE). We used cost of equity that is calculated using CAPM to determine the Economic Value Added (EVA).The EVA measures whether the companies have created shareholders' value during the estimating period. We selected the sample period of 2000 to 2005 years and we applied the monthly ending prices of common stocks of each company for the regression. The monthly ending prices of All Share Price Index (ASPI) are used as the market proxy. To estimate the beta, we applied market model. It was found that almost all the companies have created value for their shareholders during the study period. To measure the market performance, we calculated Jensen's alpha for each company and according to Jensen's alpha we found that the market performance is not satisfactory in most plantation companies. These results are important for Corporate Managers undertaking risk calculations, for fund managers making investment decision and, amongst others, for investors who wish to assess value of their investments.
\end{abstract}

\section{Introduction}

The Capital Asset Pricing Model (CAPM) of Sharpe (1964) and Lintner (1965) has received considerable attention in financial studies. In its simplest form, the CAPM predicts that the excess return of a stock should be proportional to the market premium. The proportionality factor is known as the 'systematic risk' or 'beta' of an asset'.

Early empirical studies on the CAPM such as Black et al. (1972) and Fama and MacBeth (1973) were supportive of the implications of the model. That is, the average return of high beta stocks was higher than the average return of low beta stocks. An early study by Levy (1977) showed that if the analyst used a shorter time horizon then, the beta estimates were biased. Fama $(1980,1981)$ provided evidence that the power of macroeconomic variables in explaining the stock prices increased with increasing time length.

The model gives us a precise prediction of the relationship that we should observe between the risks of an asset and its expected return. This relationship

\footnotetext{
${ }^{1}$ See Campbell (2000) Cochrane (1999) for a survey of the recent developments in the finance literature in general and asset pricing in particular.

() 2006 Sabaragamuwa University Journal, vol 6, no. 1,pp 68-81 68
} 
serves two vital functions. First, it provides a benchmark rate of return for evaluating possible investments. For example, if we are analyzing securities, we might be interested in whether the expected return we forecast for a stock is more or less than its "fair" return given its risk. Second, the model helps us to make an educated guess as to the expected return on assets that have not yet been traded in the market place.

Estimation of expected return or cost of equity for individual stocks is central to many financial decisions such as those relating to portfolio management, capital budgeting, and performance evaluation. The two main alternatives available for this purpose are a single- factor model (or Capital Assets Pricing Model (CAPM) and the three-factor model suggested by Fama and French (1992). Despite a large body of evidence in the academic literature in favour of the Fama and French model, for estimation of portfolio returns, practitioners seem to prefer CAPM for estimating cost of equity (see, for example, Bruner, Eades, Harris, \& Higgins, 1998; Graham \& Harvey, 2001).

Since the development of the CAPM in the early 60s, many tests, especially in the USA, have been performed in order to measure how well the model stands in the presence of real life conditions. In this paper, we use CAPM and Jensen's alpha to evaluate the company performance in Sri Lankan market context. The objectives of this study are investigating the company specific risk and market risk, measuring the performance of the plantation companies and investigating whether the companies have created value for the shareholders.

\section{Issues in Research Design}

As a result of the Size effect, the book value and market value of common stock is not positively correlated in developing markets when compared to financially developed countries (Banz, 1981). This is a contradicting situation, because the CAPM developed with the mark firms is higher than that of larger firms. Stattman (1980), and Lanstein (1985) find that average returns on US stocks are positively related to the ratio of a firm's book value of common equity, (BE) to its market value, (ME). Further Chan, Hamao, and Lakonisshok (1991) find that Book-toMarket equity, BE/ME, also has a strong role in explaining the cross-section of average returns on Japanese stocks. Basu (1983) shows that earnings-price ratios (E/P) help to explain the cross-section in tests that also include Size, and Market beta. In addition to this, Ball (1978) argues that E/P is a catchall proxy for unnamed factors in expected returns. As empirical evidence is largely inconsistent with the Capital Assets Model in a developed market scenario, it is useful to examine the nature of these relationships in an emerging stock market such as Sri Lankan. Further, there have been no published studies on this aspect in the Sri Lanka market.

\section{The CAPM and the Real World}

In limited ways, portfolio theory and the CAPM have become accepted tools in the practitioner community. Many investment professionals think about the distinction between firm-specific and systematic risk and are comfortable with the 
use of beta to measure systematic risk.. Still the nuances of the CAPM are not nearly as well established in the community. For example, the compensation of portfolio managers is not based on alphas calculated relative to the security market line. What can be made of this?

New ways of thinking about the world (that is, new models or theories) displace old ones when the old models become either intolerably inconsistent with data or when the new model is demonstrably more consistent with available data. For example, when Copernicus overthrew the age-old belief that the earth is fixed in the centre of the universe and that the starts orbit about it in circular motions, it took many years before astronomers and navigators replaced old astronomical tables with superior ones based on his theory. The old tools fit the data available from astronomical observation with sufficient precision to suffice for the needs of the time. To some extent, the slowness with which the CAPM has permeated daily practice in the money management industry also has to do with its precision in fitting data that is precisely explaining variation in rates of return across assets.

The CAPM was first published by Sharpe in the Journal of Finance in 1994 and took the world of finance by storm. Douglas (1969) was the first to cast doubt on the empirical content of the model. Douglas found damning evidence on two counts. First, contrary to the predictions of the theory, non-systematic risk did seem to explain average returns. Seconds, the estimated security market line was too shallow, that is its inept was greater than the risk free rate, implying that defensive stocks $(\beta<1)$ tended to have positive alphas, while aggressive stocks(with $\beta>1$ ) tended to have negative alphas.

Four years later, Miller and Scholars (1972) published a paper demonstrating formidable statistical problems that hinder a straightforward test like that of Douglas. They estimated the potential error that may have resulted from each step of Douglas's procedure and sure, enough, they were able to rationalize his findings.

But Miller and Scholar's explanation does not itself provide positive evidence that the CAPM is valid. Later studies most notably those of Black, Jensen and scholars (1972), and Fama and MacBeth (1973), used procedures designed to address the various econometric problems. The most important of these was to test the CAPM using cleverly constructed portfolios to diminish the statistical noise resulting from firm specific risk. But even these efforts could not establish the validity of the CAPM.

While all this accumulating evidence against the CAPM remained largely within the ivory towers of academia, Roll's (1977) paper entitled 'A Critique of Capital Assets Pricing Tests' shook the practitioner world as well. Roll argued that since the true market portfolio can never be observed, the CAPM is necessarily untestable.

The publicity of the new classic 'Roll's critique' resulted in popular articles such as 'Is Beta Dead ?' That effectively slowed the permeation of portfolio theory through the world of finance. This is quite ironic since, although Roll is absolutely correct on theoretical grounds, some tests suggest that the error introduced by using a broad market index as proxy for the true, unobserved market portfolio is perhaps the lesser of the problems involved in testing the CAPM. 
Fama and French (1990) completed a study that dealt the CAPM an even harsher blow. It claimed that once you control for a set of widely followed characteristics of the firm, such as the ratio of market value to book value, the firm's beta does not contribute anything to the prediction of future returns. The Economist and the New York Times picked up this time the piece even before it was published in the Journal of Finance.

This latest critique became the central topic of an academic conference and a slew of studies. None of these has been published yet, but the gist of the emerging results is that Fama and French's conclusions are hampered by subtle problems in statistical technique.

The latest studies, employing the most powerful techniques to date, show that systematic risk does help explain rates of return. This is what keeps the CAPM alive and useful in the world of economics regulation.

\section{Competitive Market Structure and the CAPM}

One of the directions of research in the Asset Pricing Models (APM) is to develop a model that can explain better the price behavior of securities in a security market. The CAPM as developed by Sharpe (1964), Lintner (1965) and Mossin (1966), was the first formal step in this direction. Then, Ross (1977) developed a more generalized model, the Arbitrate Pricing Theory (APT) model. Though the CAPM and the APT are desired under different sets of assumptions, both provide one fundamental result - a linear relationship between Expected Return $E(R)$ and a measure of systematic Risk. The linear relation between expected return and systematic risk in the CAPM and the APT is mainly because of the competitive market structure. Further generalization of the asset pricing models with the competitive market structure assumption will be a trivial exercise, as it would always result in a linear relation.

\section{Objectives of the Research}

This study aims to achieve several objectives coupled with the main objective

Primary Objective

- To measure the market performance of the Plantation Sector

\section{Secondary Objectives}

- To measure the company specific risk and market risk

- To examine shareholders' value

- Compare the performance of the companies

\section{Methodology}

A model describing the relationship between risks and expected return is used in the pricing of risky securities. CAPM says that the expected return of a security or a portfolio equals the rate on a risk-free security plus a risk premium. If this expected return does not meet or beat the required return, then the investment should not be undertaken.

Estimating expected return is crucial for many financial decisions, such as investment decisions, capital budgeting decisions and performance evaluation using measures such as EVA. From two recent surveys, Bruner, Eades, Harris, and Higgins (1998) and Graham and Harvey (2001), the Capital Asset Pricing 
Model (CAPM) was found to be the model most favoured by practitioners for doing this. Academics also commonly base estimates of expected return on CAPM. The reason for this widespread use of CAPM is probably its apparent ease of implementation.

The CAPM equation for the Security Market Line is given as

$$
E\left(R_{i}\right)=R_{f}+\beta_{i}\left\lfloor E\left(R_{m}\right)-R_{f}\right\rfloor
$$

Where,

$$
\begin{aligned}
& E\left(R_{i}\right)=\text { The expected return on security } \\
& R_{f}=\text { The risk-free rate } \\
& \beta_{i}=\text { The systematic risk defined as } \frac{\operatorname{Cov}\left(R_{i}, R_{m}\right)}{\sigma^{2}} \\
& E\left(R_{m}\right)=\text { The expected return on market portfolio }
\end{aligned}
$$

\subsection{Beta Estimation}

The Capital Asset Pricing Model is essentially the reduction of Modern portfolio theory into a single factor model- with that the single factor being called Beta. Instead of a matrix of co -variances between all securities in the market, there is only one covariance coefficient, beta the covariance between a security and the market.

The standard method of estimating beta is to regress historical returns of company's stocks against the return on the market for the same period (sample period is five years and the

number of observation is 60). In Sri Lankan market we use the ${ }^{2}$ All Share Price Index (ASPI) as the market return. The formula is:

$R_{i}=\alpha+\beta\left(R_{m}\right)+\varepsilon_{i}$

Where,

$$
\begin{gathered}
\alpha=\text { The intercept of the regression } \\
\beta=\text { solpe }=\frac{\text { Co variance }\left(R_{i}, R_{M}\right)}{\sigma_{m}^{2}}
\end{gathered}
$$

2 The ASPI measures the movement of share prices of all listed companies. The ASPI is based on market capitalization. Weighting of shares is conducted in proportion to the issued ordinary capital of the listed companies, valued at current market price (i.e. market capitalization). 


\subsection{Estimating the risk premium}

The selected companies are high liquid, frequently traded and profit making companies. Therefore as a proxy for determining the market risk premium the dividend growth model is applied. Assuming that the stock market prices the securities correctly, this method employs the following equity valuation model to generate an expected return for the market; then the risk free rate is deducted from the expected return to arrive at the equity risk premium. The same method was applied by Gunesekara(2004) to calculate the risk premium.

$$
V=\frac{D_{i}}{E\left(R_{i}\right)-g}
$$

Solving the above equation we can derive the following formula

$$
E\left(R_{i}\right)=\frac{D_{i}+(V \times g)}{V}
$$

\subsection{Evaluating Company Performance}

The required rate of return determined by CAPM provides a market-based measure of the return required by shareholders for investing in the firm. This method is consistent with Gunasekarage (2004). This is the cost of equity capital of the firm that can be used as the benchmark rate for evaluating performance of investment proposals. The return on equity (ROE) can be compared with the CAPM-based required return on equity to determine whether company managers have worked for the best interest of shareholders by investing in value creating investment projects. For this purpose the equity Economic Value Added (EVA) is applied. It can be calculated as follows.

$$
\text { Equity } \mathrm{EVA}=(\mathrm{ROE}-\mathrm{Ke}) \text { (Equity Invested in the Firm) }
$$

The non-traditional method of measuring EVA is the operating profit approach. As defined by Stewart (1991), EVA is net operating profit minus appropriate charge for the opportunity cost of all capital in an enterprise. In this paper we use traditional method of accounting profit to measure the EVA.

The evaluation criterion is that if the EVA is a positive figure, the company is creating more wealth for investors and if it is negative, it is destroying the shareholders' wealth. To evaluate the return performance of the companies, the following formula is used by rearranging the CAPM

$$
\begin{aligned}
& R_{I}=R_{f}+\beta\left(R_{m}-R_{f}\right) \\
& R_{i}=R_{f}+\beta R_{m}-\beta R_{f} \\
& R_{f}=R_{f}(1-\beta)+\beta R_{m}
\end{aligned}
$$

Using the equation (c ) with the regression equation $\left(R_{i}=\alpha+\beta\left(R_{m}\right)\right)$ the comparison of $\alpha$ in the regression equation with $R_{f}(1-\beta)$ in the rearranged 
version of the CAPM equation provides the measure of performance of shares relative to CAPM. This measure is called as 'Jensen's alpha' and it is calculated as:

$$
\text { Jensen's.Alpha }=\alpha-\left\lfloor R_{f}(1-\beta)\right\rfloor
$$

The evaluation criteria are

If the Jensen's alpha is positive the shares have performed well and if it is negative the shares have performed badly.

\subsection{Assumption of the Model (CAPM)}

The CAPM can be used to find prices of risky assets. The theory of (Sharpe, 1964) predicts a

linear relation between risk and return of the firm:

$$
E\left(R_{i}\right)=R_{f}+\beta_{i}\left\lfloor E\left(R_{m}\right)-R_{f}\right\rfloor
$$

In the above equation, for a given risky asset $i ., \beta_{i}$ is the sensitivity of the return of assets $i$ to movements of the return of the market, and it is defined as the normalized covariance between the return of the risky asset and the return of the market portfolio. High values of $\beta$ indicate a riskier asset and low values of $\beta$ indicate a more secure asset (in the limit, the return of asset $i$ will tend to the risk-free rate as $\beta$ approaches zero).

This model applies in markets with perfect information where all investors are utility maximizers and have similar expectations about the mean and standard deviation of the return of every risky asset. An asset with zero $\beta$ yields a riskfree rate at which every investor can borrow or lend. Also, in this world, there is a portfolio where every asset in the economy is included, proportional to its market value, and by definition, its $\beta$ is 1.0 .

Eq. (1) and the above assumption indicate that every asset in a given market will adjust its price until the expected return adjusted for risk generates a return equal to the return predicted by Eq. (1). In other words, every asset must lie on the security market line (a line that will intercept the vertical axis at the risk-free rate and will have a slope equal to the risk premium in the market). Note here that every investor is concerned only with the systematic risk, which is with the risk of the market as a whole, because the unique risk is diversified away by a wellbalanced portfolio. For this reason, $\beta$ is the only concern investors have when they value securities.

\subsection{Data and the sample}

We selected plantation sector to estimate the CAPM and to measure its performance. The plantation sector is a newly listed sector in the Colombo Stock Exchange (CSE) and it is a growing industry, which contributes a considerable portion to the Gross Domestic Product (GDP). The employment generation of 
this sector is also much higher than in the other sectors. Therefore several stakeholders such as current shareholders, prospective investors, fund managers, bankers and employees will get benefits from this paper.

We gathered monthly ending prices of all the plantation companies form the CD of data library, which is issued by the CSE. To avoid problems which result from thin trading and to keep the analysis manageable, only the stocks, which are traded more than $75 \%$ of the market open days in the estimation period, are included. In addition to that we consider the Market Capitalization, ROE, EPS and regular availability of data to finalize the sample. According to the above criteria and availability of data throughout the sample period, the following companies are selected for the analysis.

Agalawatte (AGLA) Plantation Ltd.

Balangoga (Bala) Plantation Ltd.

Hapugastenne (HAPU) Plantation Ltd.

Kegalle (KGAL) Plantation Ltd.

Kotagala (KOTA) Plantation Ltd.

Kelani Valley (KELA) Plantation Ltd.

Kahawatte (KAHA) Plantation Ltd.

Talawakelle (TALA) Plantation Ltd.

Udapussellawa(UDA) Plantation Ltd.

Watawala (WATA) Plantation Ltd.

The underlining theory for CAPM is quite specific in its recommendation of index; it specifies that a value-weighted index consisting of all the assets in the world should be used. Since only a small fraction of assets in the world trade on stock exchanges, it is impossible to construct such an index, so a proxy must be used instead. Therefore the most commonly used proxy is the value-weighted All Share Price Index (ASPI) in Sri Lanka. This is consistent with the recent studies of Jan and Paula (2005). They have used Standard and Poor's Composite Index as the market proxy. As the risk-free rate, the government 12 month Treasury bill rate is applied. The reason for using this rate is that its risk is zero and companies are valued on the basis of long-term future cash flows generated by them.

\section{Empirical Results}

Table 1: Summary Statistics of Companies

\begin{tabular}{|l|r|c|c|}
\hline Company & an & Variance & $\begin{array}{r}\text { Std. } \\
\text { Deviation }\end{array}$ \\
\hline AGAL & 0.01 & 0.0116 & 0.10 \\
BALA & 27 & 0.0120 & 78 \\
HAPU & - & 0.0153 & 0.10 \\
KGAL & 0.0048 & 0.0160 & 98 \\
KOTA & 0.00 & 0.0154 & 0.12 \\
KELA & 27 & 0.0128 & 38 \\
KAHA & 0.01 & 0.0158 & 0.12 \\
TALA & 15 & 0.0068 & 66 \\
UDA & - & 0.0137 & 0.12 \\
WATA & 0.0027 & 0.0134 & 42 \\
& 0.01 & & 0.11 \\
& 27 & & 35 \\
\hline
\end{tabular}




\begin{tabular}{|r|r|r|r|}
\hline & 18 & & 0.126 \\
0.00 & & 0.08 \\
& 18 & & 24 \\
& - & & 0.11 \\
& 0.0060 & & 74 \\
& 0.00 & & 0.11 \\
27 & & 59 \\
\hline
\end{tabular}

We run the regression on monthly ending prices of each of the following companies with the market index for the period of 2000/20001 to 2005/2006. Therefore the number of observation in the regression is 60 . Table 1 shows the output summary of Mean, Variance and Std. deviation of ten companies and Table2 shows the same values for the residuals.

Table 2: Summary Statistics of Residuals

\begin{tabular}{|c|c|c|c|}
\hline Company & $n^{\text {Mea }}$ & Variance & $\begin{array}{c}\text { Std. } \\
\text { Deviation }\end{array}$ \\
\hline $\begin{array}{l}\text { AGAL } \\
\text { BALA } \\
\text { HAPU } \\
\text { KGAL } \\
\text { KOTA } \\
\text { KELA } \\
\text { KAHA } \\
\text { TALA } \\
\text { UDA } \\
\text { WATA }\end{array}$ & $\begin{array}{c}\text { 1.85E-18 } \\
\text { 6.36E-19 } \\
3.01 \\
\text { E-18 } \\
5.09 \\
\text { E-18 } \\
1.16 \\
\text { E-18 } \\
9.02 \\
\text { E-18 } \\
\text { 1.39E-06 } \\
\text { - } \\
0.00047 \\
3.23 \\
8 E-18 \\
6.47 \\
3 E-18\end{array}$ & $\begin{array}{c}0.0115 \\
0.0100 \\
0.0138 \\
0.01015 \\
0.0105 \\
0.0067 \\
0.0110 \\
0.0046 \\
0.0114 \\
0.0079\end{array}$ & $\begin{array}{l}0.1075 \\
0.1001 \\
0.1175 \\
0.1007 \\
0.1028 \\
0.8226 \\
0.1052 \\
0.0680 \\
0.1071 \\
0.0890\end{array}$ \\
\hline
\end{tabular}

\section{Systematic Risk and Unsystematic Risk}

The calculation of systematic and unsystematic risk is shown only for the Agalawatte plantation and the calculations for other companies are shown in Table 3 that shows the systematic and unsystematic risk of all the sample companies.

\subsection{Agalawatte Plantation}

The output of regression model can be explained as follows. The intercept of the regression is 0.0149 and the slope of the coefficient is -0.1083 the regression equation for the AGLA is written as follows.

$$
R_{A G L A}=0.0149-0.1083(R M)
$$


The slope coefficient, which represents the beta of the firm, indicates that the shares in this company are -0.1083 times as risky as the market index, which has a beta of 01 . The company's beta is not statistically significant. The return of AGLA is not significantly influenced by the return on the market index. The beta coefficient has a standard error of 0.1878 . The true beta of the company can take values between -0.4843 and 0.2676 with a $95 \%$ level of confidence.

The $R^{2}$ of the model is 0.0057 . This indicates that $0.57 \%$ of the variation of the AGLA return is explained by the variation in the return of market index. In other words $0.57 \%$ of the risk of the company comes from market sources which is known as the systematic risk while the rest $99.43 \%$ can be attributable to firm specific factors that is known as unsystematic risk.. Total risk of the company can be calculated as follows.

Systematic risk $=\beta^{2} \sigma^{2}=(0.1083)^{2}(0.0056)=0.0000668$

Unsystematic risk $\sigma^{2}(e i)$ (Residual mean square $)=0.01157$

Total risk $=$ systematic risk + unsystematic risk

$$
\begin{aligned}
\sigma_{A G L A}{ }^{2} & =0.0000668+0.01157 \\
& =0.01163
\end{aligned}
$$

Table 3: Systematic and Unsystematic Risk of the Companies

\begin{tabular}{|l|c|c|}
\hline Company & $\begin{array}{c}\text { Systematic Risk } \\
\left(\beta^{2} \alpha^{2}\right)\end{array}$ & $\begin{array}{c}\text { Unsystematic } \\
\text { Risk }\left(\alpha^{2}\right)\end{array}$ \\
\hline AGAL & 0.0000668 & 0.0115 \\
BALA & 0.00201 & 0.0100 \\
HAPU & 0.00150 & 0.0138 \\
KGAL & 0.058 & 0.0101 \\
KOTA & 0.0048 & 0.0105 \\
KELA & 0.0060 & 0.0067 \\
KAHA & 0.0048 & 0.0110 \\
TALA & 0.0021 & 0.0046 \\
UDA & 0.023 & 0.0114 \\
WATA & 0.000018 & 0.0079 \\
\hline
\end{tabular}

According to Table 3, unsystematic risk components is higher than the systematic risk component in most companies. In other words company specific factors are mostly affected for the fluctuation of the market prices of shares in plantation sector than the market factors. As far as the plantation sector is concerned, the performance is closely related to the weather factors such as rain and drought prevailing in the country. On the other hand, the plantation sector is badly influenced by the union actions of Ceylon Workers Congress (CWC). These factors can be attributable to the high unsystematic risk of these companies. 


\subsection{Evaluating Performance}

We measure the performance of the companies only for the financial year 2003/2004. To generate the expected return, we need risk-free rate in April 2003 and the equity premium for the market. The 12-month Treasury bill Rate at the beginning of April 2003 was 9.18.

We adopt the implied equity risk premium approach to find the risk premium for the Sri Lankan Market. During the five-year period the market dividend yield was $6.5 \%$ to $3.2 \%$. Therefore average annual growth rate can be computed with the following formula.

$$
g=\left[\left\{\frac{0.032}{0.065}\right\}^{\frac{1}{5}}\right]-1
$$

$-0.1321$

The dividend growth rate is negative during this period. The expected dividend growth in 2004 was

$$
[0.032(1-0.1321)]
$$

\section{$2.7 \%$}

The market capitalization at the beginning of 2003 was 194 billion. Therefore the expected dividend for the market for the year 2003 was $(194 x 0.027)$ Rs. 5.23 billion.

Applying the following equation, we receive the expected return for the market

$$
E\left(R_{M}\right)=\frac{5.23+194 X(-0.1321)}{194}=-10.5 \%
$$

Thus, the equity risk premium for the market was $(-10.5 \%-9.18 \%)=-20.3 \%$. Now we can calculate the required rate of return for the beginning of the 2003/2004 period for each company as follows.

$$
\begin{gathered}
E\left(R_{A G L A}\right)=0.098+(-0.1083)(-0.203)=11.9 \% \\
E\left(R_{B A L A}\right)=0.098+0.5996(-0.203)=-2.37 \% \\
E\left(R_{\text {HAPU }}\right)=0.098+0.5186(-0.203)=-0.72 \% \\
E\left(R_{\text {KGAL }}\right)=0.098+1.023(-0.203)=-10.9 \% \\
E\left(R_{\text {KOTA }}\right)=0.098+0.9271(-0.203)=-9.0 \% \\
E\left(R_{\text {KELA }}\right)=0.098+1.043(-0.203)=-11.3 \% \\
E\left(R_{\text {KAHA }}\right)=0.098+0.8879(-0.203)=-8.2 \% \\
E\left(R_{\text {TALA }}\right)=0.098+0.6183(-0.203)=-2.7 \% \\
E\left(R_{U D A}\right)=0.098+0.6421(-0.203)=-3.2 \%
\end{gathered}
$$




$$
E\left(R_{\text {WATA }}\right)=0.098+0.9871(-0.203)=-10.2 \%
$$

According to the above calculation we can observe that the required rate of return is negative in all companies except Agalawatte. The major reason for this is the average annual growth rate has become a negative figure due to the declining trend of the market divided yield. But in the case of Agalawatte, the beta is more than 1.0. As a result, its required rate of return has become a positive figure in this company.

To evaluate the performance of companies in the financial year 2003/2004 and during the estimation period of the market model, we calculate equity EVA and Jensen's alpha respectively for each company. The EVA is calculated using the Eq.4 as under:

Equity EVA = (ROE-Ke) (Equity Invested in the Firm)

The EVA and the Jensen's alpha calculation is shown in the text only for the Agalawatte plantation. We have summarized EVA and the Jensen's alpha for other companies in table-4.

\subsection{Agalawatte Plantation}

The ROE of Agalawatte for the year $2003 / 2004$ is $12.06 \%$ and the cost of equity as calculated by using CAPM is $11.9 \%$.Equity invested during the year amounts to Rs.891 million. Now Equity EVA can be calculated as follows.

$$
E V A_{A G L A}=(0.1206-0.119)(891)=1.42 \text { million }
$$

The EVA of Watawala is 1.42 million which means that the company has created wealth of investors by 1.42 million during the period. From the regression output, the intercept $(\alpha)$ is equal to 0.0149 ; the average risk free rate for the period is 0.0081 . Now the monthly Jensen's alpha for the company is calculated as follows MonthlyJensen's Alpha $=0.0149-[0.0081(1-(-0.1083))]=0.006=0.6 \%$

This should be converted to the annual rate for the study and it is done as follows

$$
\text { Annual_Jensen's Alpha }=\left\lfloor(1+0.006)^{12}\right\rfloor-1=0.07=7.4 \%
$$

The company has outperformed the market during the estimation period, generating an annual excess return of $7.4 \%$ to its shareholders.

Table 4: Performance of Companies based on Jensen's Alpha and Shareholders' wealth

\begin{tabular}{|l|c|c|c|}
\hline $\begin{array}{c}\text { Company } \\
\text { Name }\end{array}$ & $\begin{array}{c}\text { EVA } \\
\text { In Million } \\
\text { (Rs.) }\end{array}$ & $\begin{array}{c}\text { Jensen's } \\
\text { Alpha \% }\end{array}$ & $\begin{array}{c}\text { Market } \\
\text { Performance }\end{array}$ \\
\hline AGAL & 1.4 & 7.4 & Satisfactory \\
BALA & 65 & -93.7 & Not Satisfactory \\
HAPU & 9.5 & -13.4 & Not Satisfactory \\
KGAL & 13 & -13.4 & Not Satisfactory \\
\hline
\end{tabular}




\begin{tabular}{|l|c|r|l|}
\hline KOTA & 5.7 & -24 & Not Satisfactory \\
KELA & 404 & -12.6 & Not Satisfactory \\
KAHA & 75 & -85.9 & Not Satisfactory \\
TALA & 139 & -15.5 & Not Satisfactory \\
UDA & 13 & -24 & Not Satisfactory \\
WATA & 133 & -19.5 & Not Satisfactory \\
\hline
\end{tabular}

Table 4 shows the calculated EVA (in million) and the Jensen's alpha for the sample companies. The positive EVA states that the company has created value for the shareholders during the period. All our sample companies have created vale for the shareholders during the year 2003/2004.It means that the companies create value for owners only when their operating income exceeds the cost of capital employed. Another crucial attribute of the EVA is that it integrates three important management functions: capital budgeting, performance appraisal and incentive compensation. Therefore this study gives a comprehensive picture about these companies for the stakeholders, particularly for the managers in making crucial managerial decisions. However EVA is just one dimension of a corporate performance measure. Other factors such as long term sustainable growth of company are equally important. The conceptual foundation of EVA, one of important shareholder value measures, is based on the 'residual income' concept.

\section{Risk Analysis of Companies}

In investors' perspective, the analysis of risk is very important as their investment decisions are highly influenced by the degree of risk associated with the investment. The degree of risk is classified in to three categories as $\beta \geq 1$ high risky stocks, $\beta<1>0$ average risky investments and $\beta<1$ low risky investment. The table -5 shows the beta coefficient of each company and proposed potential investors for each company based on the degree of risk.

Table 5: Classification of Companies based on risk

\begin{tabular}{|c|c|c|c|}
\hline Company Name & Beta & Degree of Risk & Proposed Investors \\
\hline AGAL & -0.1083 & Low risky & Defensive \\
BALA & 0.5996 & Average risky & Moderate \\
HAPU & 0.5186 & Average risky & Moderate \\
KGAL & 1.023 & High risky & Aggressive \\
KOTA & 0.9271 & Average risky & Moderate \\
KELA & 1.043 & High risky & Aggressive \\
KAHA & 0.8879 & Average risky & Moderate \\
TALA & 0.6183 & Average risky & Moderate \\
UDA & 0.6421 & Average risky & Moderate \\
WATA & 0.9871 & Average risky & Moderate \\
\hline
\end{tabular}

According to Table 4 almost all the companies have crated wealth for the shareholders during the period which indicates that the management of these companies have invested excess funds in positive NPV projects. An important attribute of economic value added is that the present value of an investment's annual EVA stream equals the investment's NPV. This makes it possible to talk about investment appraisal in terms of EVA rather than NPV provided. However in almost all the companies, the Jensen's alpha gets negative values except 
Agalawatte which indicates that these companies have badly performed in the market

\section{Conclusion}

Based on the results obtained in this study, we conclude that the unsystematic risk component is higher than the systematic risk in the plantation sector which means that the fluctuation of the market price of stocks is mostly influenced by company specific factors such as weather condition, production capacity and CWC union actions. If the companies diversify their investment they can reduce the unsystematic risk component. However the beta of most companies is less than 1.0 which is the market risk. Therefore it can also be concluded that the risk of investing in the plantation sector is low risky as compared to market risk.. Another important finding of this paper is that the management of these companies has worked for the best interest of the shareholders by creating positive EVA. In other words, the companies have undertaken positive NPV projects during the period. However EVA is just one dimension of corporate performance measure. Other factors such as long term sustainable growth of company should be considered. Positive EVA and positive NPV represent the increase of shareholders' wealth. But according to the Jensen's alpha, almost all companies have performed badly during this period.

\section{References}

Banz, R.(1981), The Relationships between Returns and Market Value and Return for NYSE Common Stock: Further Evidence?. Journal of Financial Economics, 9(1), pp.3-18

Eugene Fama and James MacBeth.1973. Risk, Return and Equilibrium: Empirical Tests. Journal of Political Economy 91. 607-636

Fama, E., \& French, K. 1993.Common risk factors in the returns on stocks and bonds. Journal of Financial Economics, 33(1),3-56

Graham, J.R., \& Harvey, C.R.2001. The theory and practice of corporate finance: evidence from the field. Journal of Financial Economics, 60(1-2), 187-243.

Gunasekarage, A., 2004. Estimating CAPM in practice and Evaluating Company Performance. Journal of the Institute of Chartered Accountants of Sri Lanka 40, 21-25.

Jan.B. \& Paula Peare.2005. Estimation of Expected Return: CAPM vs Fama and French. International Review of Financial Analysis 14, 407-427.

Lintner, J., 1965. The valuation of risk assets and the selection of risky investments in stock portfolios and capital budgets. Review of Economic Statistics 47,1429-1445

Maximiliano and Gonzalez, F., 2001.CAPM performance in the Caracas Stock Exchange 10,333-341 
Mossin, J., 1996. Equilibrium in a capital asset market, Econometrica 22, 265290.

Sharpe, w., 1964. Capital asset prices: a theory of market equilibrium under conditions of risk. Journal of Finance 19, 425-442

Stewart, G.B. 1991. The Quest for Value: A Guide for Senior Managers, New York : Harper Business. 